\title{
Струйный метод получения проводящего рисунка печатной платы
}

\author{
Ф. Бараковский ${ }^{1}$, С. Ванцов, к. т. н. ${ }^{2}$, Ф. Васильев, к. т. н. ${ }^{3}$
}

УДК 621.3.049.75::621.793 | ВАК 05.11.14

\begin{abstract}
Трудности, связанные с эксплуатацией полноразмерной гальванической линии для металлизации печатных плат (ПП), могут быть оправданы для крупносерийного производства, чего нельзя сказать о мелкосерийном [1]. Однако в России основным типом производителей печатных плат на данный момент являются именно мелкосерийные заводы, а чаще - цеха в составе предприятий, в продукцию которых электронные узлы входят составной частью. Эти предприятия, как правило, не располагают достаточным бюджетом для покупки современной гальванической линии от производителя, что вынуждает их приобретать оборудование, уже бывшее в употреблении. Последнее приводит к ухудшению качества металлизации. Но от качества металлизации существенно зависит то, насколько надежным будет конечное изделие [2]. Это побуждает искать новые, более совершенные решения.
\end{abstract}

\section{НЕДОСТАТКИ МЕТАЛЛИЗАЦИИ \\ В ГАЛЬВАНИЧЕСКОЙ ЛИНИИ}

В России не менее 90\% компаний для металлизации печатных плат используют традиционный процесс с этапом химического меднения [3]. Этот процесс состоит из восьми стадий и 12 промывок заготовок между ними (табл. 1) [4], для его осуществления требуется громоздкая гальваническая линия, состоящая как минимум из шести ванн, обслуживание которых представляет собой довольно трудоемкий процесс. Более перспективной, но еще не до конца освоенной технологией является прямая металлизация с использованием, например, палладиевого активатора, включающая пять стадий и семь промывок. В обоих вариантах металлизация проводящего рисунка и отверстий занимает существенное место в цикле производства печатных плат в отношении трудоемкости и времени, затраченного на весь процесс металлизации [5].

Кроме того, в процессе металлизации для каждой стадии используются сложные и дорогостоящие растворы, параметры которых очень сложно поддерживать в требуемом диапазоне, причем дополнять некоторые из них можно только этими же растворами [6]. Контроль состояния растворов, а также организация их экономного использования представляют собой одну из главных

МАИ (НИу), магистрант, barakovskyfa@gmail.com.

МАИ (НИУ), доцент, vancov@medpractika.ru.

МАИ (НИу), заведующий кафедрой, fedor@niit.ru. задач эксплуатации гальванических линий, для ее решения на предприятиях существуют специализированные отделы.

Таким образом, использование гальванических линий, по крайней мере в мелкосерийном производстве, имеет ряд недостатков:

- большие физические габариты гальванической линии и целый ряд затрат, связанных с ее эксплуатацией;

- необходимость содержать специализированное подразделение для контроля растворов;

- экологические проблемы, обусловленные нахождением ванн на открытом воздухе и сливом отработанных растворов.

Все это в конечном итоге приводит к увеличению стоимости выпускаемой продукции.

\section{СТРУЙНЫЙ МЕТОД}

В качестве альтернативы используемым сегодня методам металлизации в гальванической линии предлагается процесс струйной металлизации. В этом процессе, не предполагающем использования системы ванн, металлизируемый объект омывается непрерывным рециркулирующим потоком нужного раствора. обработка заготовки в каждом растворе происходит поочередно в одной камере, из которой растворы немедленно стекают по трубам в соответствующие резервуары-накопители системы рециркуляции. 
Можно ожидать, что такой метод даст целый ряд существенных преимуществ по сравнению с методами металлизации, основанными на применении многосекционных гальванических линий. Струйный процесс рассчитан на проведение металлизации печатных плат в одном устройстве, поскольку так можно выполнять кондиционирование, промывку, активацию и все другие процессы, подразумевающие обработку заготовки в каком-либо растворе. Такая установка будет во всех отношениях более простой в эксплуатации, чем обычная гальваническая линия, а отсутствие значительного числа крупногабаритных ванн позволит сократить объемы используемых растворов. Возможны реализация более удобного контроля состояния растворов и сокращение времени полного цикла металлизации.

К преимуществам такого процесса также относится его селективность: технолог может выбрать нужные параметры потока (рабочее сечение, скорость истечения, общий расход), менять область контакта потока с заготовкой в соответствии с геометрией ее металлизации -такая возможность принципиально недоступна линии, в которой заготовки вводятся в раствор путем погружения. В струйном методе плотность тока зависит уже не только от силы тока питания, но и от площади сечения потока; изменяя последнюю при неизменной силе тока, можно без дефектов металлизировать участки ПП с разной площадью металлизации. Это особенно полезно по отношению к маленьким площадям металлизации, что в первую очередь относится к проводящему рисунку ПП.

Наконец, такой процесс металлизации куда проще полностью автоматизировать, чем гальваническую линию, автоматизация которой начинается и заканчивается на автоматическом перемещении заготовок по ваннам

Может возникнуть опасение, что при использовании струйного метода будет сложно получать требуемую толщину гальванического покрытия в операции электрохимического осаждения меди. Однако механизм осаждения работает с одинаковой эффективностью как при значительной, так и при небольшой площади контакта электролита с обрабатываемой поверхностью; реальную же проблему, состоящую в обеспечении равномерности толщины покрытия по площади платы, можно решить, например, использованием выравнивающих добавок. Поглощаясь на участке металлизации, где высота осажденного покрытия больше, чем на остальных, эти добавки препятствуют дальнейшему осаждению меди на этом участке до тех пор, пока остальные не выровняются с ним по толщине покрытия.

\section{ЭКСПЕРИМЕНТ}

Для подтверждения работоспособности предложенного метода проведен качественный эксперимент, в котором

\section{MC \\ 14 \\ 49

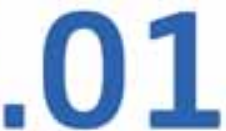 \\ navimatrix \\ by Module}

Трёхчастотный навигационный приемник

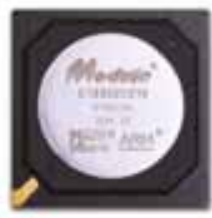

На базе отечественного навигационного процессора K1888BC018

Предназначен Аля построения высокоточной навигационной аппаратуры потребителей (НАП)

\section{Сантиметровая точность}

Работа в трехчастотных диапазонах: INOHACC L1OF, L2OF, L3OC GPS L1 C/A, L2CM, L5

Anпаратная подцержка Galileo, BeiDou и QZSS Темп навигационного решения $20 \mathrm{rL}$ Библиотека высокоточной навигации RTKLib 
проверялась возможность выполнения струйным методом операции гальванического меднения.

Синтезирован электролит следующего состава:

- $\mathrm{CuSO}_{4} \times 5 \mathrm{H}_{2} \mathrm{O}-90$ г/л;

- $\mathrm{H}_{2} \mathrm{SO}_{4}$, плотность 1,84г/ $\mathrm{CM}^{3}-200 г /$;

- $\mathrm{NaCl}-0,125 г / л$;

- добавка J-PLATECU-400-6 мл/л;

- вода до 1 л.

Таблица 1. Стадийность процессов металлизации печатных плат

\begin{tabular}{|c|c|}
\hline Процесс & Прямая металлизация \\
\hline с химическим & с использованием \\
\hline меднением & палладиевого активатора \\
\hline Очистка поверхностей & Очистка поверхностей \\
\hline Промывка & Промывка \\
\hline Промывка & Промывка \\
\hline Микротравление & Предактивация \\
\hline Промывка & Активация \\
\hline Промывка & Промывка \\
\hline Предактивация & Промывка \\
\hline Активация & Ускорение \\
\hline Промывка & Промывка \\
\hline Промывка & Промывка \\
\hline Ускорение & Антиокислитель \\
\hline Промывка & Промывка \\
\hline Промывка & Сушка \\
\hline
\end{tabular}

\section{Химическое меднение}

Промывка

Промывка

\section{Гальваническая затяжка}

Промывка

\section{Антиокислитель}

Промывка

Сушка

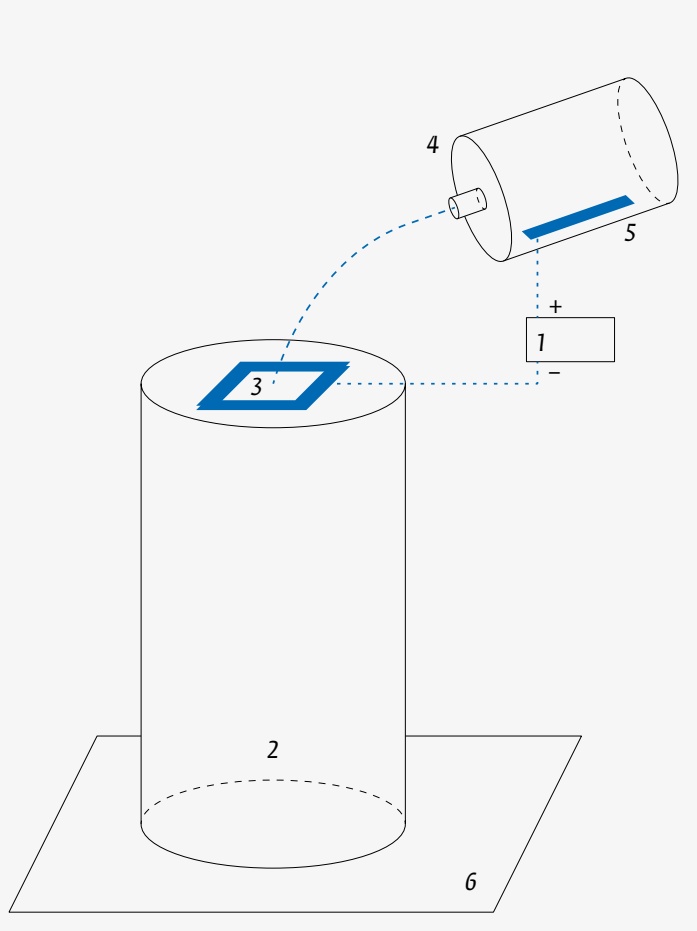

Рис. 1. Схема лабораторной установки для проверки работоспособности метода струйной металлизации: 1 - блок питания с возможностью ограничения по току; 2 - емкость из стекла, в которую стекает электролит с заготовки; 3 - заготовка, подключенная к минусу БП; 4 - емкость из стекла, содержащая электролит; 5 - электрод, подключенный к плюсу БП; 6 - рабочий стол

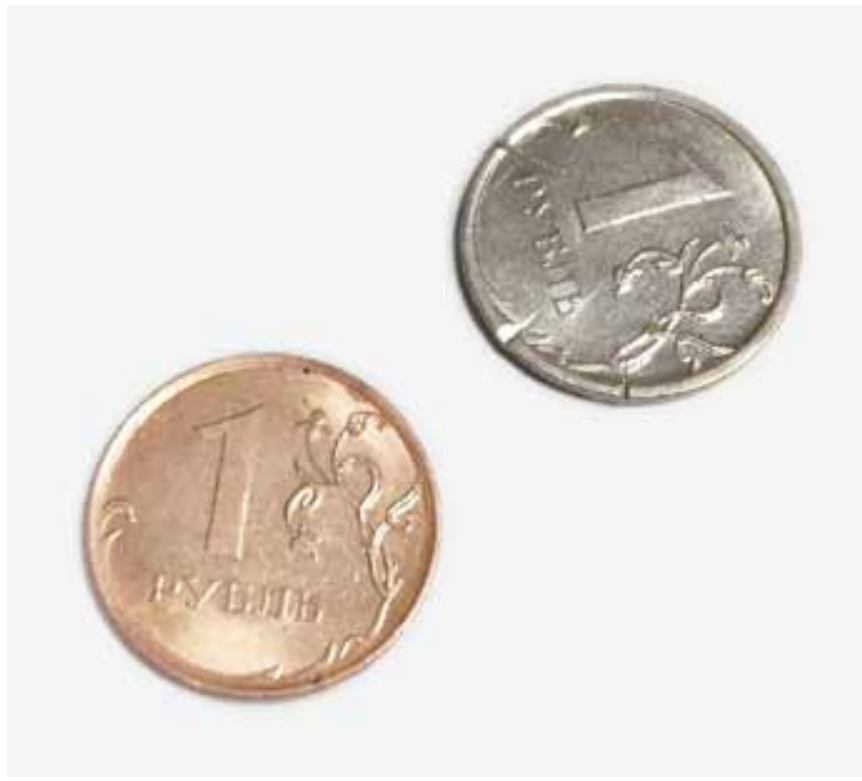

Рис. 2. Металлизированная (слева) и неметаллизированная заготовки 


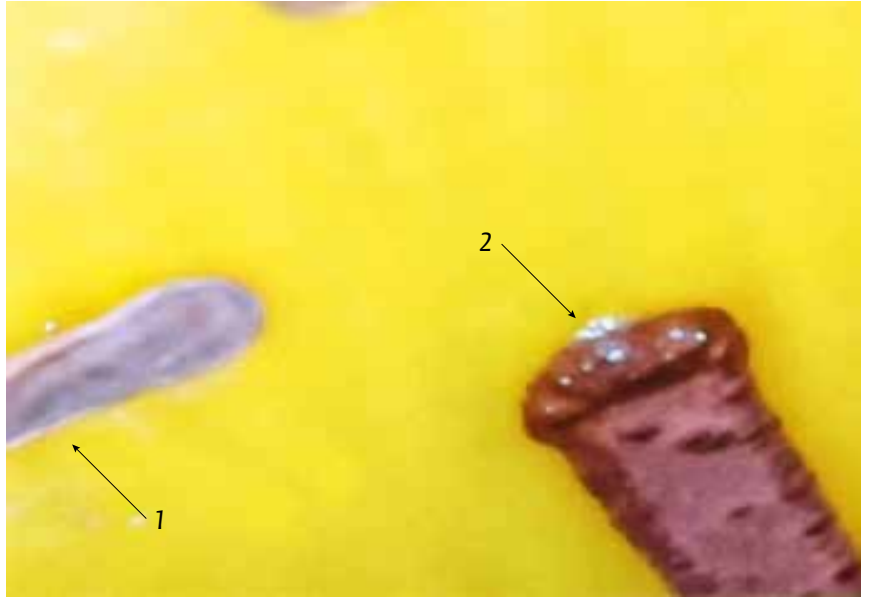

Рис. 3. Металлизация ПП: 1 - активированное покрытие проводника до осаждения меди; 2 - металлизированный проводник после гальванического осаждения меди. Сфотографировано с 20-кратным увеличением

В эксперименте, проводившемся на лабораторной установке, схема которой приведена на рис. 1, на исследуемую заготовку, подключенную к условному минусу блока питания (БП), непрерывной струей лился электролит, содержащий в своем объеме электрод, подключенный к условному плюсу БП.
Объемный расход электролита составлял примерно 0,017 л / с, то есть за минуту был израсходован 1 л электролита. За это время при токе в 0,06 А металлизировалась заготовка (монета) с площадью поверхности 630 мм² (рис. 2)

Следующий эксперимент проводился с печатными платами. Их дорожки, которые планировалось покрыть медью, имели суммарную площадь поверхности, много меньшую площади заготовки, использованной в предыдущем опыте. Ввиду этого величина тока 0,06 А оказалась значительно выше значения, достаточного для металлизации. Результат эксперимента при том же объемном расходе, что и в предыдущем опыте (0,017 л / с), представлен на рис. 3.

Можно видеть, что на поверхности металлизированного проводника выражен эффект "собачьей кости», связанный, помимо высокой плотности тока, с тем, что в эксперименте не использовались выравнивающие присадки

\section{ОЦЕНКА РЕЗУЛЬТАТОВ ЭКСПЕРИМЕНТА}

Исходя из проведенного эксперимента можно сделать следующие выводы:

- металлизация проводящего рисунка печатной платы предлагаемым методом возможна и происходит не менее эффективно, чем при металлизации
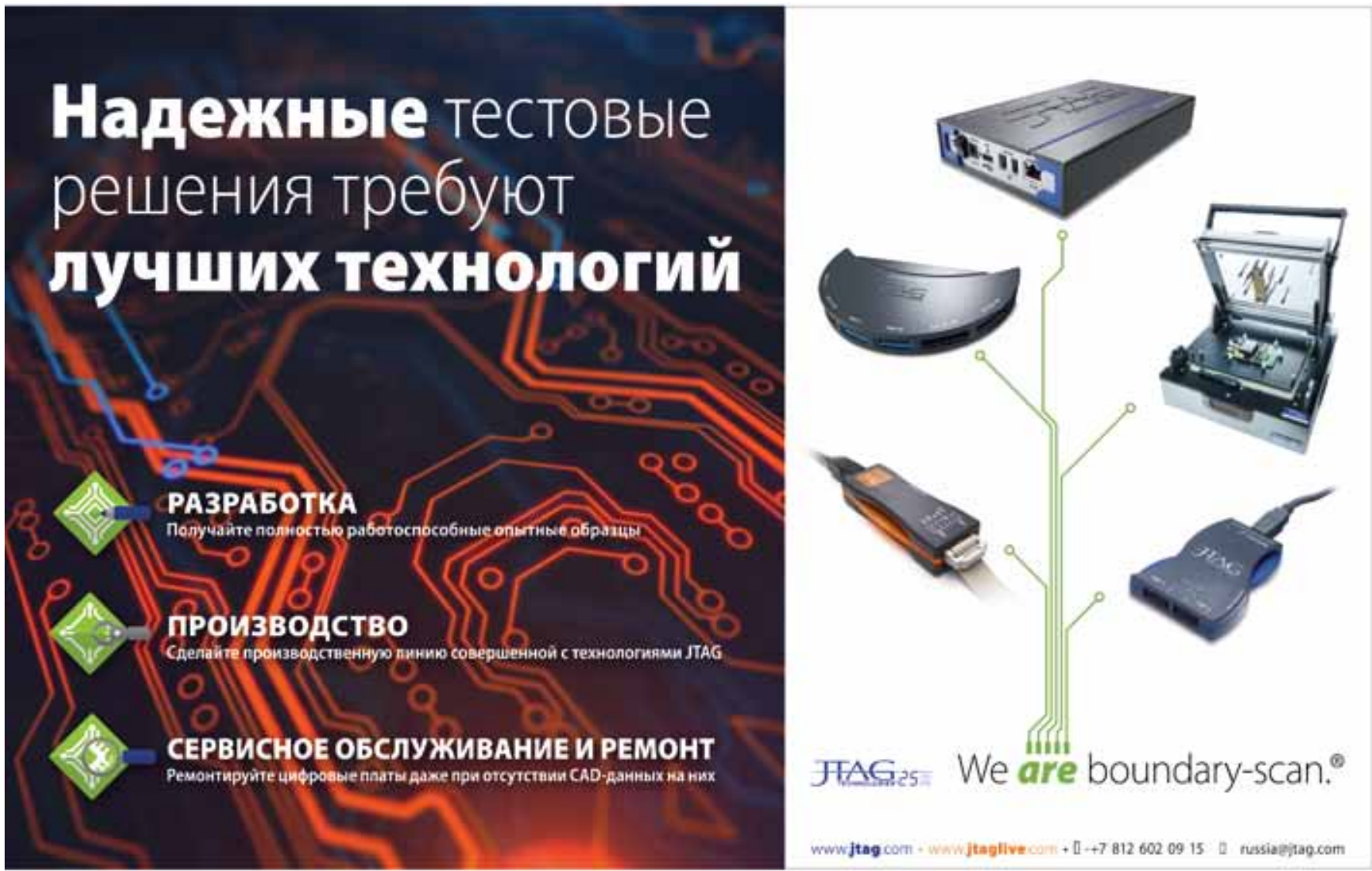
печатных плат стандартными методами;

- ток металлизации существенно зависит от площади поперечного сечения потока электролита;

- металлизация дорожек печатной платы происходит при минимальных значениях силы тока, в первую очередь вследствие маленькой площади поверхности проводящих дорожек;

- поток электролита при соударении с заготовкой может оказывать полирующее действие, обеспечивая меньшую шероховатость осажденного покрытия. Это, помимо лучших электрических свойств, особенно на высоких частотах, делает проводящую поверхность менее подверженной окислению.

\section{ЗАМКНУТАЯ СИСТЕМА СТРУЙНОЙ МЕТАЛЛИЗАЦИИ}

Обобщим преимущества струйного метода на следующем примере. На рис. 4 изображена схема установки металлизации печатных плат струйным методом с системой рециркуляции рабочих растворов. Конфигурация установки на схеме соответствует режиму электрохимического осаждения меди.

Замкнутый цикл циркуляции электролита минимизирует его расход в процессе эксплуатации. В такой установке возможно проводить полный цикл металлизации, поочередно обрабатывая заготовку в соответствующих растворах. Так как за каждым процессом цикла металлизации ПП следуют одна или несколько промывок, поддержание в чистоте рабочей камеры реализуется как сопутствующий эффект от операций промывки. Для особо ценных реагентов, используемых в процессе, возможно предусмотреть воздушное компримирование в камере для того, чтобы обеспечить остаткоотдачу раствора в соответствующий резервуар, в котором, при возникновении такой необходимости, возможна регенерация раствора (если регенерация данного раствора предусмотрена изготовителем). Важно, что предлагаемая схема позволит применить все наработки по контролю растворов в проточных трубах, что упрощает задачу полной автоматизации такой установки.
Более эффективная эксплуатация химических растворов, безусловно, оказывает положительный эффект на экологический след такой технологии.

\section{ЛИТЕРАТУРА}

1. Степанов В. Прямая металлизация печатных плат: да или нет? // Компоненты и технологии. 2002. № 22 С. 140-141.

2. Медведев А. Каким быть российскому производству электроники? Часть 1 // Компоненты и технологии. 2007. № 69. С. 231-238.

3. Флёров В.Н. Химическая технология в производстве радиоэлектронных деталей. - М.: Радио и связь, 1988. 106 с

4. Ильин В.А. Технология изготовления печатных плат. Л.: Машиностроение, Ленинградское отд-ние, 1984. 77 с.

5. Lundguist J., Медведев А., Салтыкова В. Системы прямой металлизации // Компоненты и технологии. 2003. № 4. С. 204-207.

6. Терешкин В., Григорьева л., Фантгоф ж. Металлизация отверстий печатных плат // Производство электроники, технологии, оборудование, материалы. 2006. № 1. C. 64-66. 


\section{TPAНСИВЕР ИЗОЛИРОВАННЫЙ RS485+DC/DC}

- ВЫСОКАЯ СКОРОСТЬ ПЕРЕДАЧИ ДАННЫХ ДО 25 М6/С

- УВЕЛИЧЕННАЯ ИЗОЛЯЦИЯ ДО 5,7 кВ

- НИЗКОЕ ЭЛЕКТРОМАГНИТНОЕ ИЗЛУЧЕНИЕ (EN55022 Class B)

- ВСТРОЕННЫЙ ИЗОЛИРОВАННЫЙ DC/DC ПРЕОБРАЗОВАТЕЛЬ

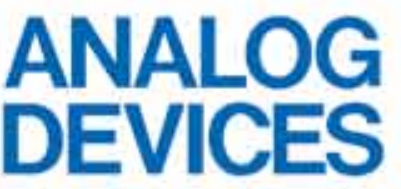

AHEAD OF WHAT'S POSSIBLE ${ }^{T M}$

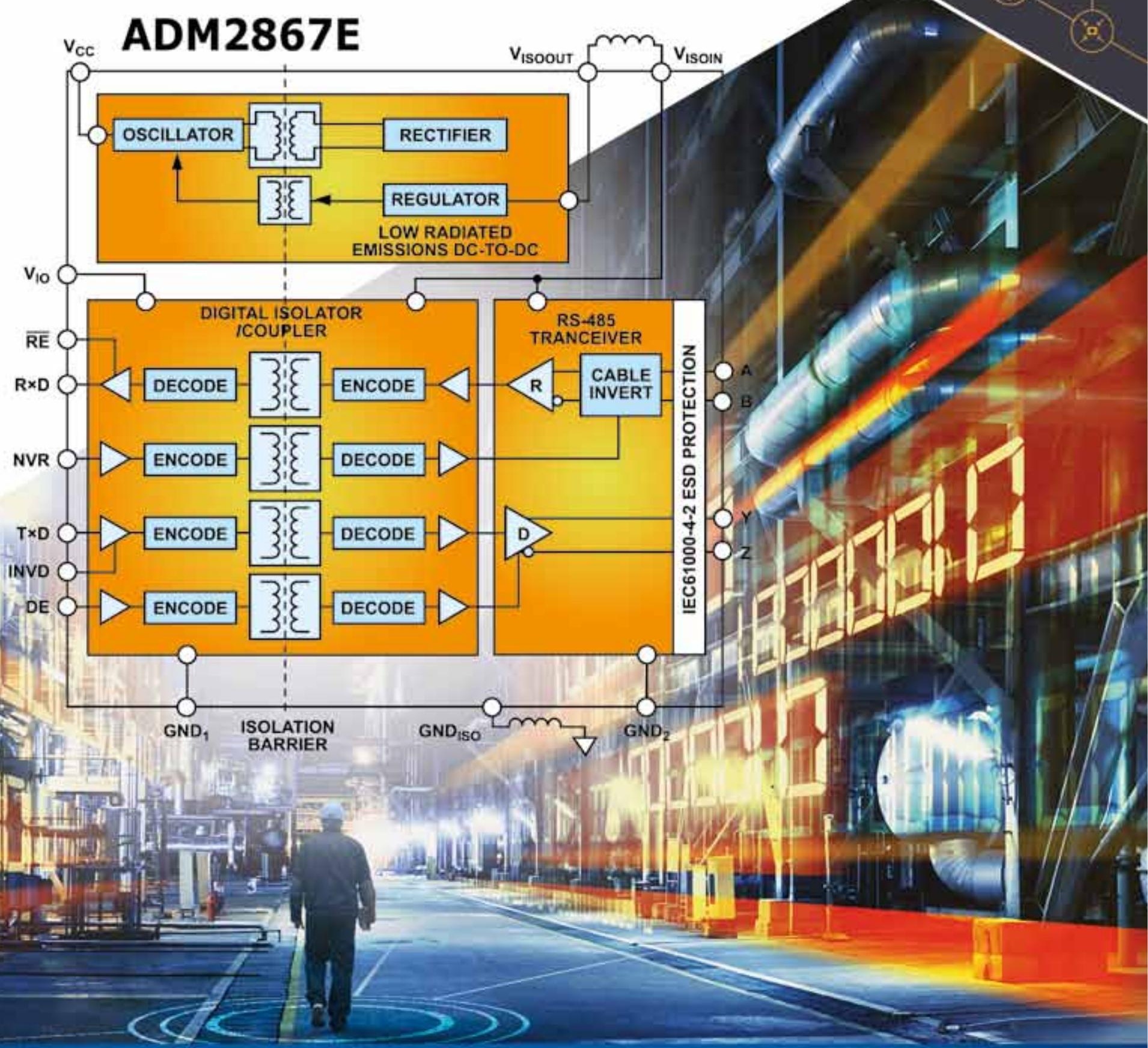

